Archives de sciences sociales des religions

112 | octobre-décembre 2000

Âme et corps : conceptions de la personne

PARFITT (Tudor), TREVISAN SEMI (Emanuela), eds., The Beta Israel in Ethiopia and Israel. Studies on the Ethiopian Jews

Surrey (G.-B.), Curzon Press, 1999, 304 p.

Régine Azria

(2) OpenEdition

Journals

Édition électronique

URL : http://journals.openedition.org/assr/20451

DOI : 10.4000/assr.20451

ISSN : $1777-5825$

Éditeur

Éditions de l'EHESS

Édition imprimée

Date de publication : 31 décembre 2000

Pagination : 163

ISBN : 2-222-96698-1

ISSN : 0335-5985

Référence électronique

Régine Azria, «PARFITT (Tudor), TREVISAN SEMI (Emanuela), eds., The Beta Israel in Ethiopia and Israel. Studies on the Ethiopian Jews », Archives de sciences sociales des religions [En ligne], 112 | octobre-décembre 2000, document 112.94, mis en ligne le 19 août 2009, consulté le 21 septembre 2020. URL : http://journals.openedition.org/assr/20451 ; DOI : https://doi.org/10.4000/assr.20451

Ce document a été généré automatiquement le 21 septembre 2020.

(C) Archives de sciences sociales des religions 


\section{PARFITT (Tudor), TREVISAN SEMI (Emanuela), eds., The Beta Israel in Ethiopia and Israel. Studies on the Ethiopian Jews}

Surrey (G.-B.), Curzon Press, 1999, 304 p.

Régine Azria

\section{RÉFÉRENCE}

PARFITT (Tudor), Emanuela Trevisan Semi (Emanuela), eds., The Beta Israel in Ethiopia and Israel. Studies on the Ethiopian Jews,Surrey (G.-B.), Curzon Press, 1999, 304 p.

1 Ensemble substantiel de textes sur les juifs d'Éthiopie, ou Beta Israel, rassemblés autour d'un thème central, celui de la transformation d'une tribu éthiopienne en une minorité réimplantée au sein d'un État moderne du Moyen-Orient, étant entendu que cette transformation est le produit d'une évolution commencée au XIX ${ }^{e}$ siècle et à ce jour inachevée. Cette évolution nous est présentée sous des angles divers. Une série d'articles concerne la période de découverte des juifs d'Éthiopie, les missions et les premiers Occidentaux au contact de ces juifs, le processus de «judaïsation » mis en place par J. Faitlovitch et les résistances qu'il rencontre auprès de son institution de tutelle, l'Alliance Israélite Universelle, réticente à voir dans ces juifs de vrais juifs. Un second ensemble de textes s'intéresse à la période d'occupation italienne. D'autres textes s'intéressent à la question des conversions : juifs convertis en Éthiopie dans le passé et aujourd'hui, attitude des autorités israéliennes face à ces convertis, cas de conversions au pentecôtisme en Israël même. La façon dont les femmes éthiopiennes vivent le changement fait l'objet de trois articles : stress engendré par le changement, baisse de la fécondité, histoire de vie. De fait, l'intégration en Israël se traduit par une « résistance au quotidien » aux fins de préserver les spécificités culturelles. Or, comme 
le montrent certaines des contributions ici rassemblées, ces spécificités (musiques, croyances, pratiques, mentalités,...) sont confrontées aux multiples facettes de la modernité culturelle, technologique, scientifique (disco-dance, vidéo, médecine). Les difficultés rencontrées sont réduites ou dépassées au terme d'un processus de négociation ou non résolues en raison d'une incompréhension mutuelle et d'une difficulté à communiquer (cf. incompréhension entre malades et corps médical). D'autres articles traitent de thèmes variés: liturgie, musique, linguistique. Le tout aboutit au constat de la fragilité et de la fluidité de l'équilibre entre intégration et survie identitaire. 